\title{
ELECTRIC INSULATION TECHNOLOGIES \\ AND CHARACTERISTICS OF MICRO-ARC OXIDATION \\ OF ALUMINUM ALLOYS OF DIAMOND GRINDING WHEEL WRAMEWORKS ${ }^{1}$
}

\section{Gutsalenko Yu. G.}

\section{INTRODUCTION}

Microarc oxidation (MAO), also plasma electrolyte oxidation (PEO) in European terminological practice, used to modify surfaces of valve metals has recently gained a new impetus. The successful use of the MAO coatings in many industries is based on their high functional and performance characteristics determined by their unique physical and mechanical properties, with a sufficiently wide thickness range (from several to hundreds of micrometers) and high adhesion with a base ${ }^{2}$.

MAO technology is a promising surface finishing process that allows you to obtain a wide range of coatings with various properties according to the requirements of their use ${ }^{3}$.

In combination with other methods, namely, electric arc deposition ${ }^{4}$ and extraction-pyrolytic decomposition ${ }^{5}$, it allows the creation of polyfunctional (antiware, heat- and corrosion-resistant, dielectric, catalytic, etc.) coatings for the surfaces of nonvalve metals. The employment of slurry electrolytes in this method widens the scope of its application to novel fields, in medicine and biology in particular ${ }^{6}$.

1 The author is grateful to colleagues for discussing of research planning and results, as well as assistance in their implementation: V. V. Belozerov and A. I. Makhatilova (MDO in the AFM mode and X-ray diffraction analysis), E. K. Sevidova and I. I. Stepanova (MAO in the GS mode), L. I. Pupan (electron microscopy).

${ }^{2}$ Mikheev, A.E., Terekhin, N.A., Statsura, V.V. et al. Bulletin of Machine Building. 2, 56-63 (2003).

${ }^{3}$ Famiyeh, L., Xiaohu, H. Mod. Concept Material Sci. 2 (1), 000526 (2019).

4 Student, M.M., Posuvailo, V.M., Veselivs'ka, H.H. et al. Mater. Sci. 53 (6), 789-795 (2018).

5 Rudnev, V.S., Medkov, M.A., Yarovaya, T.P. et al. Journal of Applied Chemistry 85 (4), 621-628 (2012).

${ }^{6}$ Borisov, A.M., Krit, B.L., Lyudin, V.B. et al. Surf. Eng. Appl. Electrochem. 52, 50-78 (2016). 
Despite the extensive experience in the use of MAO coatings and the development of numerical modifications of the method ${ }^{7}$, in recent years the technology has become intensively developed due to the widespread use of light metals and alloys (aluminum, titanium, magnesium) in different industrial sectors ${ }^{8}$. The need for providing stable characteristics of coatings - high hardness, low porosity, required tribological properties, corrosion resistance, wear resistance, thermal and electrical insulation parameters - has also increased ${ }^{9}$. Traditional MAO methods do not exhaust all possibilities, and there is a renewed interest in investigation to develop new prospects for the effective application of the coatings appear. Today's interest in investigating the dielectric properties of micro-arc oxide coatings on aluminum alloys is related to the instrumental application of such alloys in diamond grinding wrameworks, which require electrical protection in high-performance technologies with direct current feed to the treatment area ${ }^{10}$.

The little information available on investigation of the dielectric properties of the coating prepared using MAO leads to the conclusion that their characteristic, namely ohmic resistance and dielectric strength, substantially depend on the metal grade and electrolysis conditions ${ }^{11}$.

Optimization of the contributing factors that affect the MAO process is performed based on one or more key coating quality criteria, as defined by the operation conditions. These usually include wear resistance, corrosion resistance, dielectric properties, thermal resistance etc.

However, much less attention is devoted to the study of microgeometry in applied research, in particular, to roughness and surface morphology. In most cases, these characteristics are of minor importance for the quality evaluation of MAO layers, except decorative coatings. The significance of the above characteristics is even more offset when the process involves removing the poorly adhered outer layer, which contributes to coating roughness increase.

7 Suminov, I.V., Belkin, P.N., Apelfeld, A.V. et al. Plasma-electrolytic modification of the surface of metals and alloys: Book 2. Technosphera, Moscow (2011).

${ }^{8}$ Walsh, F.C., Low, C.T.J., Wood, R.J.K. et al. Trans. Inst. Metal Finish. 87 (3), 122-135 (2009).

9 Filyak, M.M., Kanygina, O.N. Bulletin of the Orenburg State University. 9 (158), 240-243 (2013).

${ }^{10}$ Gutsalenko, Yu.G., Sevidova, O.K. Reliability of instrument and optimization of technological systems. 40, 35-43 (2017). 106-110.

${ }^{11}$ Tokarev, A.V. Bulletin of the Kyrgyz-Russian Slavic University 12 (10), 
At the same time, certain applications of MAO coatings require considering the surface roughness and morphology of the produced surfaces, besides their key functional properties. The combination of the microgeometry (predominantly, mean profile deviation $R_{a}$, which is the most informative roughness indicator) and surface morphology characteristics allows to create complementary surface quality evaluation systems for many practical applications of MAO coatings.

Feasibility study of using MAO layers as electrical insulation (dielectric) coatings on metal wrameworks of diamond grinding wheels ${ }^{12}$ demonstrated that their bore surface $R_{a}$ roughness index must meet specific requirements and be equal to $2.5 \mu \mathrm{m}$, according to the drawings. Similar requirements can be also applied to other parts with rigid joint connections.

At the same time, the connection between porosity as a structural component of the surface of coatings with their dielectric properties ${ }^{13}$ which are decisive when used in a diamond-abrasive tool with direct current to it in combined electrophysical grinding processes is extremely poorly understood ${ }^{14}$.

The purpose of this work to study MAO technology capabilities as applied to deformable aluminum alloys and evaluate the dielectric properties of the resulting coatings, influence of factors on the roughness and morphology of the surface of dielectric coatings and to determine the rational conditions of their formation.

\section{Organization of experiments and research}

The experimental samples were made of deformable aluminum alloys D16T (1360) and AK6 (2124) GOST 4784-97 (ISO 209-1) which are used for the manufacturing of the diamond grinding wheels wrameworks.

The dimensions of the samples are 20x15x1.5 mm (D16T - sheet hire) and $\varnothing 30 \mathrm{~mm}, 5 \mathrm{~mm}$ thick (AK6 - calibrated bar). The initial surface roughness amounted to from $R_{a}=1.2 \mu \mathrm{m}$ (on samples from AK6) to $R_{a}=1.6 \mu \mathrm{m}$ (on samples from D16T).

${ }^{12}$ Sevidova, E., Gutsalenko, Yu., Rudnev, A. et al. LNME: Advances in Design, Simulation and Manufacturing II: DSMIE 2019 Conf. Proc., 302-310 (2020)

13 Gutsalenko, Yu.G., Sevidova, E.K., Stepanova, I.I. Surf. Engin. Appl. Electrochem. 55 (5), 602-606 (2019).

${ }^{14}$ Gutsalenko, Yu.G. Diamond-spark grinding of high functionality materials. Cursor, Kharkov (2016). 
The coatings were formed in indentical conditions in the three samples. The data were registered by measuring the respective parameters in five points for the different sides of of each sample. The error of the measurtment results did not exceed $10 \%$.

Two electric modes of MAO most widely employed in the modern technology, namely an anode galvanostatic (GS) one and a mode of autofalling power (AFP) using an anode-cathode (alternating) current, were investigated. The processes were accomplished using transformer and capacitor power sources, respectively.

The investigations in the GS mode involved the influence of anode current density on the dielectric properties of the formed MAO coatings. The current density amounted to $5,7.5,10$, and $15 \mathrm{~A} \cdot \mathrm{dm}^{-2}$. The duration of the electrolysis was determined using the principle that in each experiment, the same charge of electricity flow through the electrolysis unit. Following the calculations, durations of oxidation of 40, 26.6, 20, and $13.3 \mathrm{~min}$ were used.

In the AFP mode, the influence of the duration of the MAO process ( 1 and $2 \mathrm{~h}$ ) in various electrolytes on the electrophysical characteristics of the coatings was evaluated. The initial current density was $20 \mathrm{~A} \cdot \mathrm{dm}^{-2}$.

On the basis of the published data and the results of preliminary experiments, for research have been taken three electrolytes of the alkalinesilicate group: first $-12 \mathrm{~g} \cdot \mathrm{l}^{-1} \mathrm{LG}$ (LG is a technical solution of the sodium liquid glass (sodium silicate) with the specific mass of $1.4 \mathrm{~g} \cdot \mathrm{sm}^{-3}$ ); second $2 \mathrm{~g} \cdot \mathrm{L}^{-1} \mathrm{KOH}+12 \mathrm{~g} \cdot \mathrm{L}^{-1} \mathrm{LG}$; third $-1 \mathrm{~g} \cdot \mathrm{L}^{-1} \mathrm{KOH}+6 \mathrm{~g} \cdot \mathrm{L}^{-1} \mathrm{LG}$. For the sake of simplicity, the electrolyte compositions are hereinafter denoted as 0:12, $2: 12$, and $1: 6$, respectively. The temperature of the solutions was maintained within a range of $20-35^{\circ} \mathrm{C}$.

The thickness of coating was determined by a nondestructive method, using the eddy current thickness indicator NOVOTEST TP-1.

The specific volume resistivity $\rho_{\mathrm{V}}$ and electric strength $E$ were adopted as main characteristics of insulating properties. The volume resistivity was measured according to GOST 6433.2 using a teraohmmeter E6-13 at an operation voltage of $100 \mathrm{~V}$. The reading of parameters was accomplished over a minute after the voltage was switched on.

The breakdown voltage was determined for an alternating current $(50 \mathrm{~Hz})$ using a laboratory set-up that included a high voltage transformer, a protective resistor $5 \mathrm{k} \Omega$, and a scheme for smooth 
regulation of the voltage. The measurtments started from the high voltage value.

$\mathrm{X}$-ray diffraction analysis of the coatings was performed using an X-ray diffraction meter DRON-3 with monochromatic radiation of a copper anode in the range of angles $2 \theta$ within 15 to $50^{\circ}$, chosen taking into account the most probable phase composition of the coatings that can be expect on the basis of previous investigations ${ }^{15}$.

Surface roughness, the arithmetic mean profile deviation $R_{\mathrm{a}}$, was measured by Surtronic 3+ profilograph-profilometer (Taylor Hobson) on the base length of $0.8 \mathrm{~mm}$.

The quality evaluation of the morphological condition of the surface layer was performed by optical microscopy using a USB-microscope Supereyes B008 and scanning electron microscopy (SEM) in secondary electron imaging mode by means of a JEOL JSM-840 microscope.

Preliminary research using panoramic micrographs (with a magnification of $15 \ldots 50$ ) allowed to determine the general morphological characteristics of the coating surface layer and to analyze the surface structure homogeneity based on the total area of samples, and to identify the presence of pores and their relative counts. The color effect features allowed to qualitatively assess the presence of different phase components.

The scanning electron microscopy analysis (with a magnification of $100 \ldots 1000$, significantly greater depth of focus and imaging at an angle $\alpha=45^{\circ}$ ) allowed to qualitatively evaluate the microrelief, i.e. amplitude parameters, the shape of the structural elements of coatings, surface patterns, stages of pore formation, pore size and depth. The research was conducted on the local area, technologically stable and pre-defined coating sections.

\section{Dielectric properties of coatings}

Analysis of the thicknesses of the MAO layers formed in the AFP mode shows (Table 1) that their value predictably depends on the composition of electrolytes and the electrolysis duration; moreover, the temporal factor predominates. In general, the thickness of coatings on D16T alloy is greater than on AK6 ones. The advantage increases with the transition to more aggressive electrolytes containing in its composition caustic alkali - from $25 . .30 \%$ in a solution of $0: 12$ to (2014).

${ }^{15}$ Dehnavi, V., Liu, X.Y., Luan, B.L. et al. Surf. Coat. Tech. 251, 106-114 
$80 \ldots 90 \%$ in a solution of $2: 12$. The probable reason of this difference is the different etching rate of intermetallic compounds entering into alloys ${ }^{16}$.

The thickness of the coatings prepared in the GS mode does not in fact depend on the current density, but it depends on electrolyte composition. As in the AFP mode, the minimal thickness $(29 \mu \mathrm{m})$ forms in a diluted alkaline-silica 1:6 solution and the maximal thickness (37 $\mu \mathrm{m})$ forms in a 2:12 solution (see Table 1).

Table 1

The thickness of the MAO coatings on deformable alloys under various electrolysis conditions, $\mu \mathrm{m}$

\begin{tabular}{|c|c|c|c|c|c|c|c|c|c|c|c|c|}
\hline \multirow{4}{*}{$\begin{array}{l}\text { Grade } \\
\text { of } \\
\text { alloy }\end{array}$} & \multicolumn{12}{|c|}{ Electrolyte } \\
\hline & \multicolumn{2}{|c|}{$0: 12$} & \multicolumn{2}{|c|}{$2: 12$} & \multicolumn{2}{|c|}{$1: 6$} & \multicolumn{2}{|c|}{$0: 12$} & & & & \\
\hline & \multicolumn{6}{|c|}{$\begin{array}{l}\text { AFP mode, initial current density } \\
20 \mathrm{~A} \cdot \mathrm{dm}^{-2}: \\
\text { electrolysis time, hours }\end{array}$} & \multicolumn{6}{|c|}{$\begin{array}{c}\text { GS mode, (electrolysis } \\
\text { time) } \cdot(\text { current density })=200 \\
\text { A } \cdot \text { min } \cdot \mathrm{dm}^{-2}: \\
\text { current density, } A \cdot \mathrm{dm}^{-2}\end{array}$} \\
\hline & 1 & 2 & 1 & 2 & 1 & 2 & 5 & 15 & 5 & 15 & 5 & 15 \\
\hline D16T & 80 & 150 & 100 & 210 & 70 & 170 & 42 & 43 & 44 & 45 & 36 & 38 \\
\hline AK6 & 60 & 120 & 55 & 120 & 40 & 90 & 33 & 34 & 37 & 37 & 30 & 29 \\
\hline
\end{tabular}

Obviously, the silicate component plays a decisive role in the rate of growth of MAO layers.

The subsequent measurement of the coatings dielectric characteristics, its specific volume resistivity $\rho_{\mathrm{V}}$ and the electrical strength $E$ indicate (Fig. 1) the predominant effect of thickness on their values. In particular, an increase in the oxidation time, and, correspondingly, of the thickness, in two times on the AK6 alloy, led to the deterioration of the $\rho_{\mathrm{V}}$ index in $4 . . .5$ times in all electrolyte solutions (see Fig. 1, a). Less pronounced this effect was displayed on the alloy D16T - the corresponding decrease was 1.9...2.5 times (see Fig. 1, $b$ ).

The fact that dielectric properties of MAO coatings worsen when their thickness increases can be explaned by inhomogeneity of the structure of the coating itself, which increases when the thickness of the oxide layer increases, and mullite, sillimanite, and other phases, distinguished by lower values of $\rho_{\mathrm{V}}$ than for $\mathrm{Al}_{2} \mathrm{O}_{3}$ appear in its structure. Moreover, the effect of trapping the current-carrying

\footnotetext{
${ }^{16}$ Chigrinova, N.M., Chigrinov, V.E., Kukharev, A.A. Powder metallurgy 5/6, 13-23 (2001).
} 
electrolyte ions and improvement of the conditions for migration and diffusion of the ions of alkali earth metal (in our case $\mathrm{K}+$ and $\mathrm{Na}+$ ) ander the action of temperature ${ }^{17}$ negatively influences the $\rho_{\mathrm{V}}$ value.

The best index $\rho_{\mathrm{v}}$ provide coatings on both alloys, formed in alkalisilicate electrolyte 1:6, the lowest - in 1.7...4 times, in a solution of 2:12. In general, the coatings obtained within 1 hour in the thickness range $40 \ldots 60 \mu \mathrm{m}$ on the AK6 alloy and $70 \ldots 100 \mu \mathrm{m}$ on the D16T one are characterized by high specific resistivity (in the range $(1 \ldots 9) \cdot 10^{9} \Omega \cdot \mathrm{m}$ ), but the relative advantage of this index (in 2...2.5 times) have MAO layers on AK6.

The electrical strength of the coatings (see Fig. 1, c, d), like the specific resistivity, unambiguously decreases with increasing thickness, although the total breakdown voltage in this case increases. The latter is associated with a decrease in open porosity and end-toend defects, which are a trouble spot, since the electrical strength of the air in them is only 3 $\mathrm{V} \cdot \mu \mathrm{m}^{-1}$.

${ }^{17}$ Pavlyus, S.G., Sobornitskiy, V.I., Sheprut, Yu.A. et al. Electronic Processing of Materials 3, 34-36 (1987). 

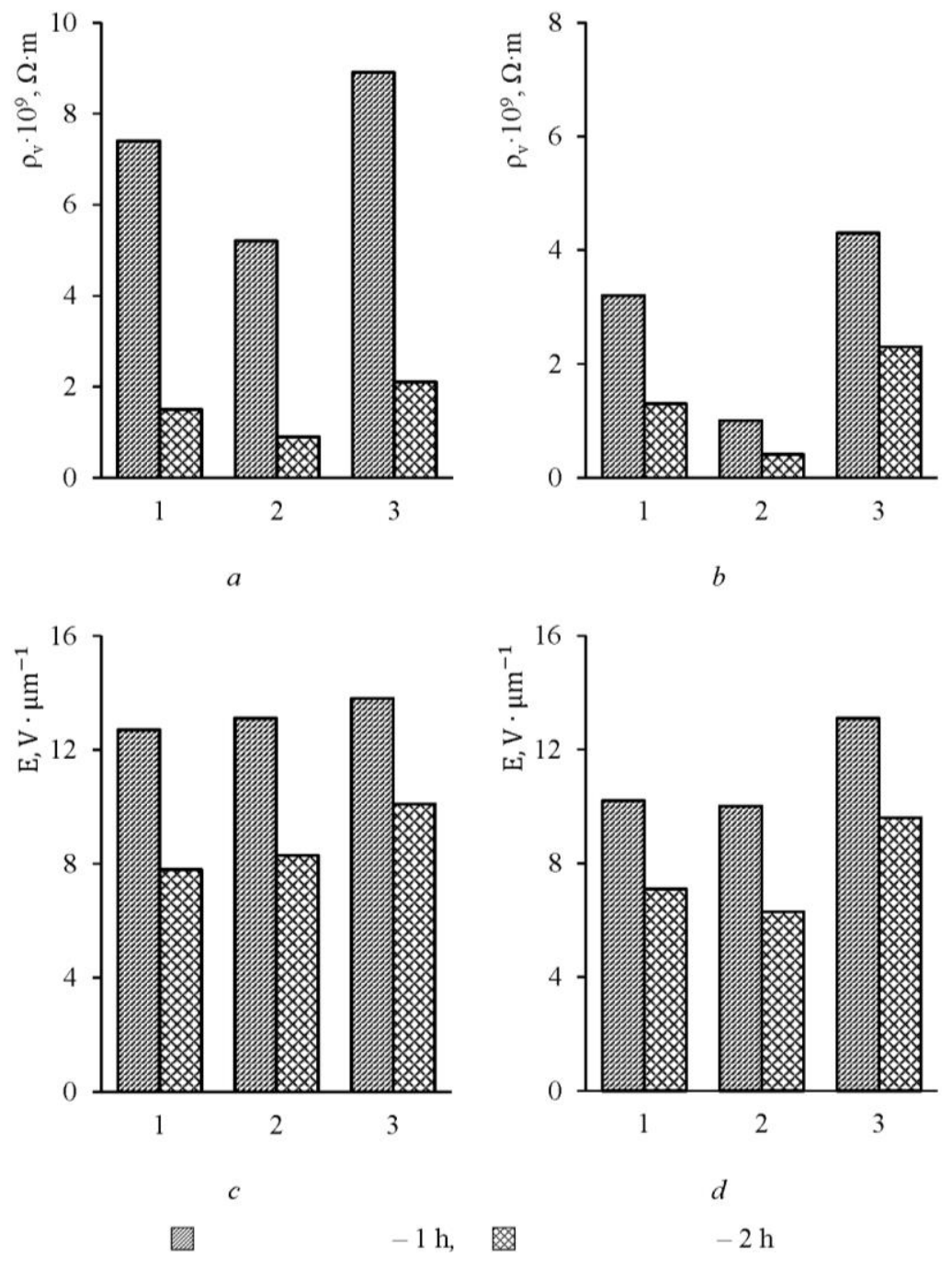

Fig. 1. Dependence of specific volume resistance $(a, b)$ and electric strength (c, d) of the MAO coatings of AK6 (a, c) and D16T (b, d) alloys from the time of oxidation under the AFP mode in different electrolytes: $1-0: 12 ; 2-2: 12 ; 3-1: 6$ 
The reasons for the $E$ deterioration with increasing the coatings thickness are the same, which lead to deterioration $\rho_{\mathrm{V}}$ - heterogeneity, the presence in the composition of aluminum oxides of different structures as well as mullites, sillimanites and other compounds with lower dielectric properties.

The index $E$ is less dependent than $\rho_{\mathrm{V}}$ on the alloy grade and the electrolyte composition, but a slight advantage of $10 . . .30 \%$ is observed in MAO coatings formed in a 1:6 electrolyte solution; in this case the value of $E$ reaches $13 \ldots 14 \mathrm{~V} \cdot \mu \mathrm{m}^{-1}$.

Both electrophysical parameters ( $\rho_{\mathrm{V}}$ more substantially) depend on the electrolyte composition. It can be said that for the AFP mode the coating formed in a 1:6 solution exhibit the best dielectric properties and those formed in a 2:12 solution exhibit relatively worse characteristics (Fig. 1).

Analysis of the dielectric properties for the coating prepared in GS mode for both alloys, AK6 (Fig. 2, $a, c$ ) and D16T (Fig. 2, $b, d$ ) allowed to note tendency when the current density $j$ increases. This can be associated with the increase in porosity that is typical for GS modes and the saturation of the composite coating by electrolyte elements.

The difference between the $\rho_{\mathrm{V}}$ values of the coatings formed in various electrolytes is more pronounced. The best result was found for the liquid glass solution $0: 12$; the worst result was obtained for solution $2: 12$, which was lower by a factor of 1.6-1.9.

The presented results are in qualitative agreement with the values of the forming voltage that become settled at the end of the MAO process in each solution independently of the current density. Respectively, the greatest voltage was observed in the silicate $0: 12$ electrolyte $-560 \mathrm{~V}$ on AK6, and $580 \mathrm{~V}$ on D16T; the least one of $520 \mathrm{~V}$ in the alkaline-silicate $2: 12$ electrolyte on both alloys. One of the reasons that the parameter $\rho_{\mathrm{V}}$ becomes worse in the 2:12 solution may be already noted above in the analysis of results in the AFM mode the elevated concentration of ions of alkaline metal, in it that leads to a relatively greater concentration of these ions in the composition of the coating. 


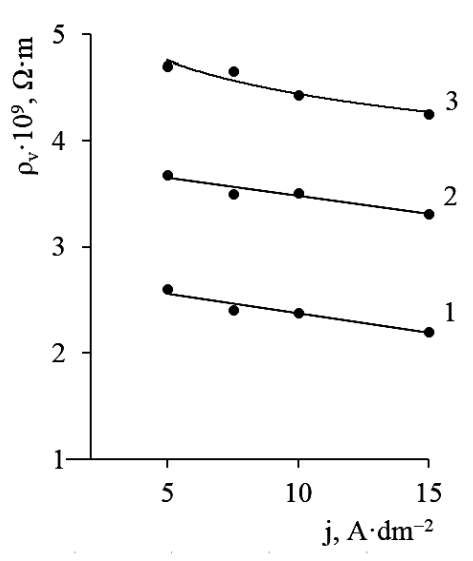

$a$

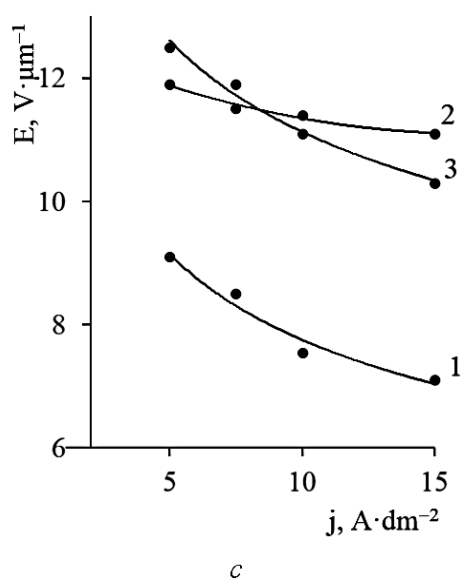

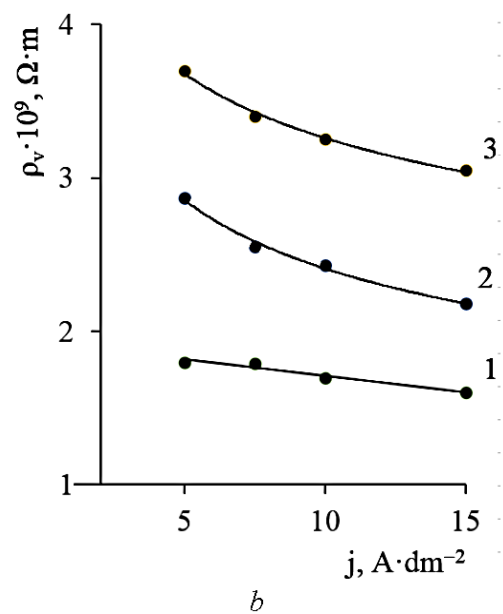

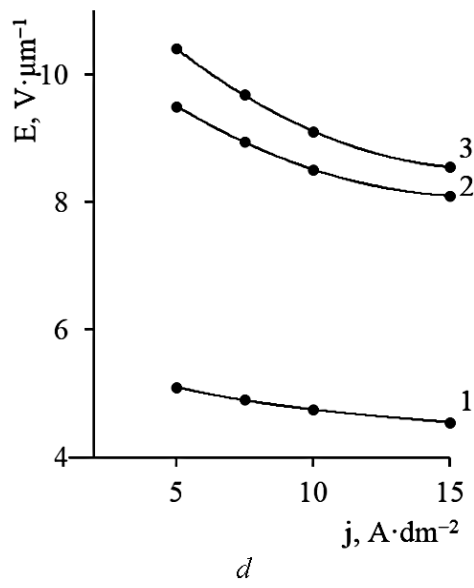

Fig. 2. Dependence of specific volume resistance $(a, b)$ and electric strength (c, d) of the MAO coatings of AK6 (a, c) and D16T (b, d) alloys from the anode current density under the GS mode in different electrolytes: 1 - 0:12; 2 - 2:12; $3-1: 6$

The character of the variation of the electric strength of the coatings versus the investigated factors for both alloys - AK6 (Fig. 2, c), and D16T (Fig. 2, d), as could be expected is similar to the dependence of the specific resistance on them. In particular, for electrolitytes 0:12 and 2:12 
the tendency of diminishing of the parameter with the increasing of the current density (curves 1 and 3 ) is retained or becomes even stronger; the influence of the qualitative and quantitative composition of the electrolytes is to some degree smooth (curves 2 and 3 ). The best values of the electric strength in GS mode - in 1:6 and 0:12 solutions.

Table 2

\section{The main phase composition of MAO coatings on AK6 alloy at various conditions of their electrolysis in time $\tau$}

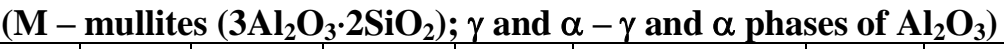

\begin{tabular}{|c|c|c|c|c|c|c|c|}
\hline $\begin{array}{l}\text { Grade } \\
\text { of } \\
\text { alloy }\end{array}$ & Mode & $\begin{array}{c}\text { Electro } \\
- \\
\text { lyte }\end{array}$ & $\begin{array}{c}j, \\
\mathrm{~A} \cdot \mathrm{dm}^{-2}\end{array}$ & $\begin{array}{c}\tau, \\
\text { мин }\end{array}$ & Phase & $I_{\gamma} / I_{m}$ & $Q_{p}, \%$ \\
\hline \multirow{9}{*}{ D16T } & \multirow{3}{*}{ AFP } & $0: 12$ & 30 & 60 & $\mathrm{M}, \gamma$, halo & 0.46 & 5 \\
\hline & & $2: 12$ & 30 & 60 & $\mathrm{M}, \gamma$, halo & 0.83 & 8 \\
\hline & & $1: 6$ & 30 & 60 & $\gamma, \mathrm{M}$ & 3.8 & 40 \\
\hline & \multirow{6}{*}{ GS } & \multirow[t]{2}{*}{$0: 12$} & 7.5 & 26.6 & $\begin{array}{c}\text { M, } \gamma \text { traces, } \\
\text { halo }\end{array}$ & 0.55 & 5 \\
\hline & & & 15 & 13.3 & $\mathrm{M}, \gamma$, halo & 0.62 & 6 \\
\hline & & \multirow{2}{*}{$2: 12$} & 5 & 40 & $\gamma, \mathrm{M}, \alpha$ traces & 1.6 & 16 \\
\hline & & & 15 & 13.3 & $\mathrm{M}, \gamma$ & 0.88 & 9 \\
\hline & & \multirow{2}{*}{$1: 6$} & 5 & 40 & $\gamma, \mathrm{M}$ & 1.8 & 18 \\
\hline & & & 15 & 13.3 & $\gamma, \mathrm{M}$ & 1.89 & 19 \\
\hline \multirow{9}{*}{ АК6 } & \multirow{3}{*}{ AFP } & $0: 12$ & 20 & 60 & $\gamma, M$ & 1.34 & 13 \\
\hline & & $2: 12$ & 20 & 60 & $\mathrm{M}, \gamma$ & 0.33 & $3-5$ \\
\hline & & $1: 6$ & 20 & 60 & $\gamma, \mathrm{M}$ traces & 10 & 100 \\
\hline & \multirow{6}{*}{ GS } & \multirow{2}{*}{$0: 12$} & 5 & 40 & $\gamma, \mathrm{M}$ & 1.19 & 11 \\
\hline & & & 15 & 13.3 & $\gamma, \mathrm{M}$ & 0.96 & 10 \\
\hline & & \multirow{2}{*}{$2: 12$} & 5 & 40 & $\gamma, \mathrm{M}$ & 2.5 & 25 \\
\hline & & & 15 & 13.3 & $\gamma, \mathrm{M}$ & 2.4 & 24 \\
\hline & & \multirow{2}{*}{$1: 6$} & 5 & 40 & $\gamma, M$ & 2.4 & 24 \\
\hline & & & 15 & 13.3 & $\gamma, M$ & 5 & 50 \\
\hline
\end{tabular}

In general, from comparison the electrophysical parameters of MAO coatings formed on both alloys using the two electric modes, it can see that the results related to the choice of the efficient electrolyte composition correlate. In all cases, the 1:6 and 0:12 solutions exhibit distinct advantages.

Analysis of the results of X-ray diffraction investigations (see Table 2) shows that the phase composition of the coatings, in particular, the quantity of $\gamma-\mathrm{Al}_{2} \mathrm{O}_{3}$ and its relationship to the mullite phase by 
radiation intensity $\left(I_{\gamma} / I_{m}\right)$ or relative estimation of the values of this ratio $\left(Q_{p}, \%\right)$ are not the determining parameters for the dielectric properties.

Obviously, these parameters of MAO coatings respond to the integral influence of all the components of the composite substance, including the radiotransparent and unidentified ones. This first of all relates to the ions of alkaline metals that worsen the dielectric properties of the coatings ${ }^{18}$; the quantity of the ions can be determined using an X-ray spectral microanalysis.

\section{Morphology and microgeometry of coatings}

On Fig. 3, $R_{a}$ values demonstrate that the surface roughness of both studied alloys after MAO, especially oxidated in the AFP mode, increases significantly. The rate of increase of its absolute value depends on the electrolyte composition and process duration in the AFP mode, and reaches a factor of $4 \ldots 6$, compared to the baseline $R_{a}$ value. A two-fold increase of the electrolysis time and, therefore, of coating thickness (Table 1) results in further $R_{a}$ increase. However, roughness increase associated with this factor is not very significant and constitutes $10 \ldots 20 \%$ (Fig. 3, $a, b$ ). The roughness increase proportional to the coating thickness can be explained by a significant coating destruction ${ }^{19}$, if the power of the solitary visually observable spark discharges increases. It is also possible to state that coating roughness is almost independent from the components of the oxidated alloys, but it is more sensitive to electrolyte composition.

In particular, the lowest $R_{a}$ value $(25-40 \%$ lower) is fixed in 1:6 solution with the minimal LG concentration. The effect of LG concentration is critical for this coating surface characteristic, if all the other factors of the MAO process being equal. This result fully correlates with the conclusions of the research ${ }^{20}$ regarding the correlation between the increasing roughness and silicate concentrations.

In the GS mode the rate of roughness increase is generally somewhat lower and is a factor of $2 \ldots 5$. Under conditions of indifference of the coating thickness to a change in current density (Table 1), $R_{a}$ dependences not only from the electrolyte composition but also of current density are manifested (Fig. 3, $c, d$ ). Last mentioned dependency

${ }^{18}$ Martin, J., Leone, P., Nomine, A. et al. Surf. Coat. Tech. 269, 36-46 (2015).

${ }^{19}$ Hussein, R.O., Northwood, D.O. In: Developments in Corrosion Protection, 201-239. InTech, Rijeka, Croatia (2014).

${ }^{20}$ Chernenko, V.I., Snezhko, L.A., Papanova, I.I. Obtaining of coatings by anode-spark electrolysis. Leningrad, Chemistry (1991). 
is not monotonic, but extremal in 0:12 and 1:6 solutions. In fact, $R_{a}$ index increases in the range of $5 \ldots 10 \mathrm{~A} \cdot \mathrm{dm}^{-2}$ and subsequently drops as current density increases till $15 \mathrm{~A} \cdot \mathrm{dm}^{-2}$. The smoothing effect could be well observed even with no auxiliary optical devices: the structure and color of the oxidated surface became significantly more homogenous with this current density.
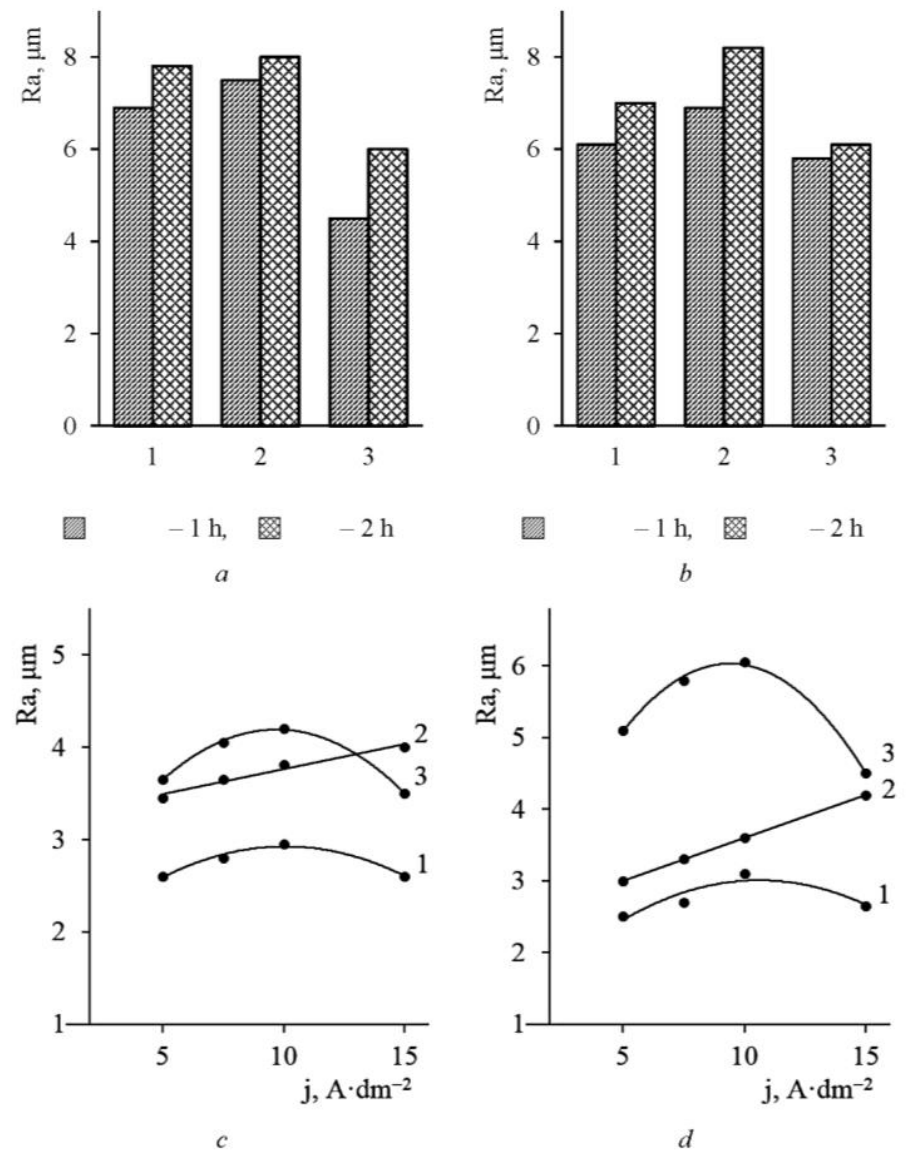

Fig. 3. Dependences of surface roughness of the MAO coatings on the time of oxidation in the AFP mode ( $a, b)$ and current density in the GS mode $(c, d)$ of AK6 (a, c) and D16T $(b, d)$ alloys in different electrolytes:

$$
1-0: 12 ; 2-2: 12 ; 3-1: 6
$$


The enhancement of $R_{a}$ index at $j=15 \mathrm{~A} \cdot \mathrm{dm}^{-2}$ can be accounted for the Joule's heat release $\left(\sim j^{2}\right)$, which is sufficient at this current density for fusion and melting to occur both within the coating layer and on the surface structures, in particular, fusion and melting of aluminum oxides and silica. A presence of concentrated alkali in 2:12 solution can offset this effect due to an increased etching action of the harsh component $(\mathrm{KOH})$, which results in the monotonic $R_{a}$ increase proportional to the current density.

Similarly to the alternating current oxidation under the AFP mode, the minimum roughness value of dielectric coatings produced under the GS mode is achieved in the 1:6 electrolyte.

It was noted above that on both alloys, the best indicators of specific volume resistance are provided by coatings also formed in the electrolyte 1: 6.

The electric strength of the coatings (see Table 1 and Fig. 1 together), as well as the specific volume resistance, decreases with increasing thickness. The latter is associated with a relative increase in open porosity (Fig. 4) and through defects, the electric strength of the air of which is only $3 \mathrm{~V} \cdot \mu \mathrm{m}^{-1}$.

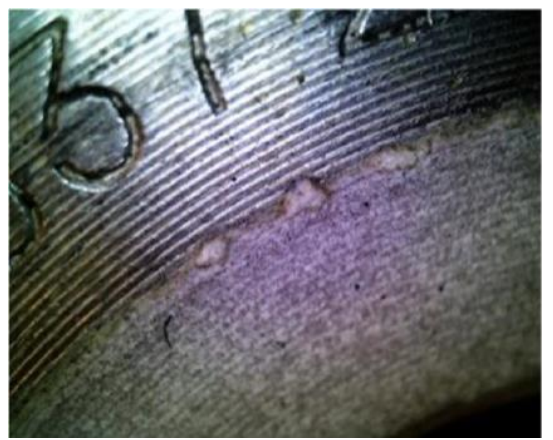

$10^{\mathrm{x}}$

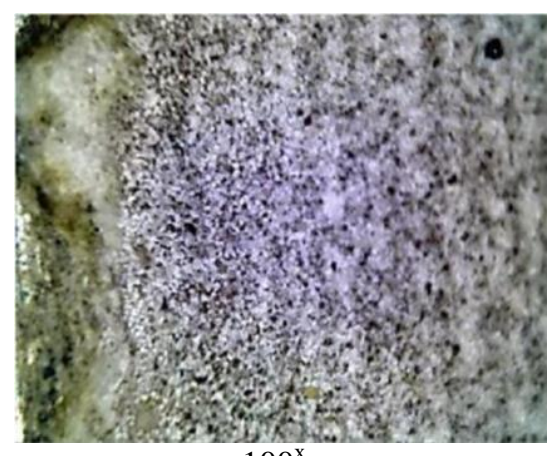

$100^{\mathrm{x}}$

Fig. 4. Microphotographs of the surface of the diamond grinding wheel wramework from AK6 aluminum alloy with a local MOA coating

The results of the electron scanning microscopy morphological research of the MAO coatings on AK6 alloy (Fig. 5) allow to make some generalizations. 


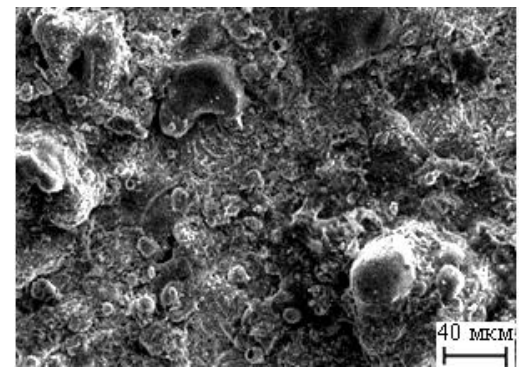

a

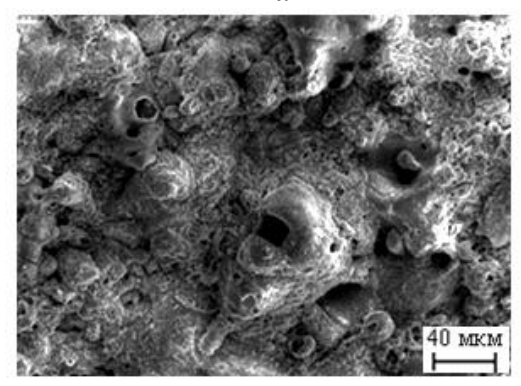

c

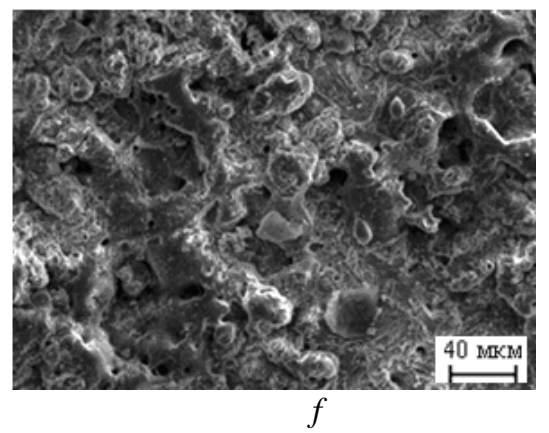

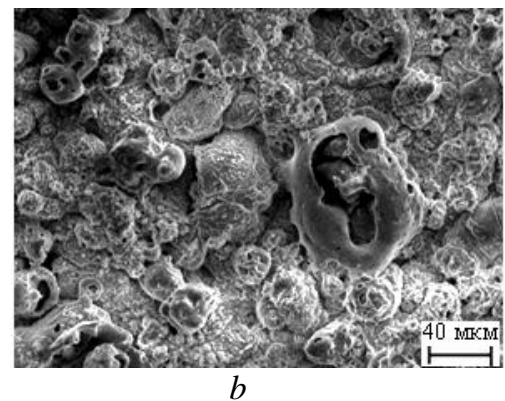

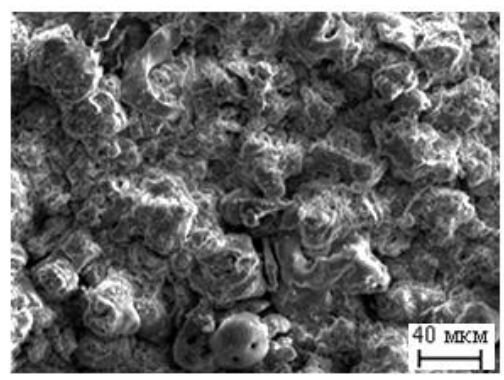

d

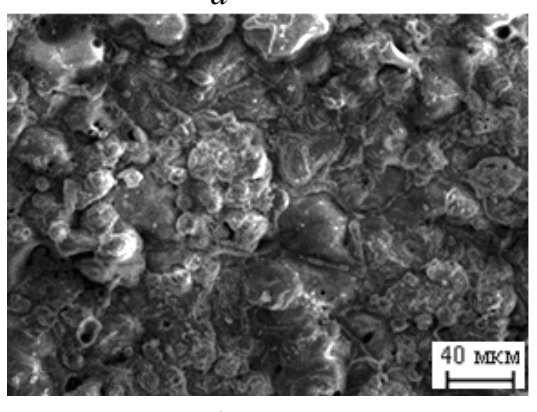

$g$

Fig. 5. Morphology of the surface of MDO coatings on AK6 alloy after AFP mode in 1 (a, c, f) and $2(b, d, g)$ hours in different electrolytes: a, b-0:12; c, d-2:12; f, g-1: 6

In particular, it is possible to state that all MAO coating surfaces produced under the AFP mode using alternating current have a welldeveloped relief with alternate peaks and valleys formed by separate conglomerates of compounds of the outer layer. 
Open and closed pores were observed on all samples in the largest field of vision of optical microscopy (1.2 mm, magnification x100). The size, relative counts and pore depth depend upon the PEO mode (electrolyte composition, duration of electrolysis).

Comparing the surface morphology of samples oxidated by the same electrolyte at different time points (see Figures 5, $a$ and 5, $b ; 5, c$ and $5 d$; $5, f$ and $5, g$ ), it is possible to state that the morphological structure becomes more developed and demonstrates more prominent relief with clear boundaries of particles in all dimensions.

This qualitatively correlates with the results of analysis of roughness $R_{a}$, which also shows a tendency to increase with the electrolysis time increasing. The $R_{a}$ change for AK6 alloy after AFP mode in various electrolytes (see Fig. 3, $a$ ) occurs in the ranges of $6.6 \ldots 7.5 \mu \mathrm{m}$; 7.5...7.8 $\mu \mathrm{m}$ and 4.7...6.0 $\mu \mathrm{m}$, respectively.

Comparing the morphology of the MAO coating surfaces produced by various electrolytes, it is possible to conclude that the difference is the most pronounced for 2:12 solution (see Fig. 3, $c$ and 3,d).

The surface morphology produced in this solution is smoother and characterized by less marked variance of amplitude parameters and convexity of the surface conglomerate particles of the coating materials, as compared to surfaces oxidated in 0:12 and 1:6 solutions.

Another prominent morphological feature is a relatively high accessible porosity of this coating. Pore sizes range from 2 to $10 \mu \mathrm{m}$ and more, some of them (predominantly, larger size pores) are quite deeply expanded. These circumstances can impair (i.e. increase) the $R_{a}$ roughness index, which was observed during the research (see Fig. 3).

On the other hand, increased porosity, particularly accessible porosity $^{21}$, can contribute to the impairment of the isolation properties which was confirmed by the results of previous research ${ }^{22}$.

The critical factor that contributes to the characteristic surface morphology in 2:12 solution is most probably the alkaline component of the $\mathrm{KOH}$ solution and its destructive action, which increases proportionally to the alkaline concentration. This can be indirectly confirmed by more moderate surface relief in 1:6 solution, where $\mathrm{KOH}$ concentration is twice as low (see Fig. 5, $f$ and 5, $g$ ).

${ }^{21}$ Curran, J.A., Clyne, T.W. Acta Mater. 54 (7), 1985-1993 (2006).

22 Gutsalenko, Yu.G., Sevidova, E.K., Stepanova, I.I. et al. Probl. At. Sci. Technol. 114, 125-127 (2018). 
An insignificant pore percentage is recorded on this surface (which is lower compared to the surface produced in 2:12 solution), pore sizes decreasing to $1 \ldots 6 \mu \mathrm{m}$. The electrolysis time increased to 2 hours results in a further reduction both sizes and quality of open pores.

In this research, the CEM study results were considered as supplementary. At the same time, they enable to interpret the coating characteristics observed by means of other techniques. This particularly pertains to the roughness parameters and dielectric properties.

Based on the morphology research results, it is possible to state that 1:6 alkaline-silicate solution $\left(1 \mathrm{~g} \cdot \mathrm{L}^{-1} \mathrm{KOH}+6 \mathrm{~g} \cdot \mathrm{L}^{-1} \mathrm{LG}\right)$ is the most appropriate electrolyte for MAO coatings formation with minimum values of roughness and porosity. It is important that the best indicators of the dielectric properties of coatings were obtained with alternating current in the AFP mode in this particular solution.

\section{CONCLUSIONS}

In general, both modes of the formation of MAO coatings provide sufficiently high parameters for $\rho_{\mathrm{V}}$ and $E$. At the same time, the absolute values of parameters $\rho_{\mathrm{V}}$ and $E$ are greated by a factor of 1.5-2.5 for the coatings on AK6 and 1.2-1.9 for the coatings on D16T which are formed using an anode-catode (alternating) current in the AFP mode at the comparable thicknesses. This may be the reason to choose this mode as a basis method for the development of technology of formation of isolation coatings on aluminium frameworks of diamond-abrasive wheels to provide an expansion of technological capabilities of machine tool technical grinding system for realization of combined electrophysical processing.

Established results do not contradict the conventional knowledge, since studies of other features of the functional quality of coatings at comparable thicknesses have established that the MAO layers obtained at alternating current are more homogeneous and less defective ${ }^{23}$, and this obviously also has a positive effect on the barrier electrophysical parameters.

It is established that the best results of the dielectric properties on both alloys $-\rho_{\mathrm{V}}=(4 \ldots 9) \cdot 10^{9} \Omega \cdot \mathrm{m}$ and $E=13 \ldots 14 \mathrm{~V} \cdot \mu \mathrm{m}^{-1}-$ provides moderately concentrated alkaline-silicate electrolyte 1:6 with relative

23 Bakovets, V.V., Polyakov, O.V., Dolgovesova, I.P. Plasma-electrolytic anodic processing of metals. Science, Novosibirsk (1991). 
mass contents of potassium alkali and sodium silicate respectively $1 \mathrm{~g} \cdot \mathrm{L}^{-1}$ and $6 \mathrm{~g} \cdot \mathrm{L}^{-1}$.

Based on the research, it was established that the formation of dielectric insulation coatings on the surface of D16 and AK6 alloys using the MAO technique results in an increase of the output $R_{a}$ value by a factor of $2 \ldots 6$, depending upon the electrolysis conditions: electrolyte composition, electricity mode, process duration (coating thickness). It was established that the lowest $R_{a}$ value for both alloys and electrical modes (AFP and GS) was provided also with the electrolyte composition 1:6.

Under the conditions of the GS regime of the formation of coatings of equal thickness, the roughness of their surface depends on the density of the anode current $j$. This dependence, within the studied values of $j$ (up to $15 \mathrm{~A} \cdot \mathrm{dm}^{-2}$ ), is extreme for solutions of $0: 12$ and $1: 6$.

Microscopic studies of the surfaces of MDO coatings allow to state a qualitative correlation of their morphological features with microgeometric roughness estimates. Taking into account the results of morphological studies of open porosity of coatings increases the objectivity of choosing a rational electrolyte composition for the formation of electrical insulating coatings not only in terms of roughness, but also in terms of functional indicators.

\section{SUMMARY}

The presented work is focused on the development of technologies for the formation of electrical insulating coatings on aluminum frameworks of diamond-abrasive wheels, which provide the expansion of technological capabilities of machine tool technical grinding systems for the implementation of combined electrophysical processing. The technological capabilities of electrical insulating microarc oxidation as applied to deformable aluminum alloys of grades D16T (1360) and AK6 (2124) GOST 4784-97 (ISO 209-1) used in the manufacture of frameworks of diamond grinding wheels in the tool industry were studied. The studies were carried out for two main in practice microarc oxidation of electric modes - anode galvanostatic with a transformer (up to $600 \mathrm{~V}$ ) current source with a current density of up to $15 \mathrm{~A} \cdot \mathrm{dm}^{-2}$ in the experiments and auto-falling power on the anode-cathode (alternating) current from a capacitor current source with a current density of $20 \mathrm{~A} \cdot \mathrm{dm}^{-2}$. The technological medium of microarc oxidation in the performed studies consisted of alkaline-silicate group electrolytes with zero, 1 and $2 \mathrm{~g} \cdot \mathrm{L}^{-1} \mathrm{KOH}$ concentration in the presence of sodium silicate at levels of 6 and $12 \mathrm{~g} \cdot \mathrm{L}^{-1}$. The temperature of the aqueous solutions was maintained in the range from normal to $35^{\circ} \mathrm{C}$. The influence of the time 
of the microarc oxidation process was evaluated in a auto-falling power mode. The data of roentgenologic studies, conventional and electron microscopy of the obtained coatings, and control of their roughness are presented and analyzed. It has been shown that microarc oxidation by its nature worsens the roughness of machined initial surfaces. The data of $\mathrm{x}$-ray studies, conventional and electron microscopy of the obtained coatings, and control of their roughness are presented and subjected to analysis. It has been shown that microarc oxidation by its nature worsens the roughness of machined initial surfaces. At the same time, the extreme nature of the dependence of the average microroughness height on the anode current density during microarc oxidation in the calvanostatic mode in electrolytes with a low concentration of the alkaline component was revealed and explained. It was shown that the data of microscopic visualization of the coating surface qualitatively correlate with the microgeometric and dielectric functional parameters of the coatings. The dielectric quality of the obtained oxide coatings was evaluated by the specific volume resistance and electric strength. The rational conditions for the formation of dielectric coatings on the studied aluminum alloys are determined. Information is presented for the practical implementation of the development of local electrical insulating coatings of a highperformance processing technology tool with the introduction of electric discharge energy into the cutting zone to maintain the functionability of grinding wheels with a diamond-metal composition of the working part.

\section{REFERENCES}

1. Mikheev, A.E., Terekhin, N.A., Statsura, V.V., Golenkova, A.A. Technological possibilities of microarc oxidation of aluminum alloys. Bulletin of Machine Building. 2, 56-63 (2003). In Russian.

2. Famiyeh, L., Xiaohu, H. Plasma electrolytic oxidation coatings on aluminum alloys: microstructures, properties, and applications. Mod. Concept Material Sci. 2 (1), 000526 (2019). URL: https://irispublishers.com/mcms/pdf/MCMS.MS.ID.000526.pdf.

3. Student, M.M., Posuvailo, V.M., Veselivs'ka, H.H., Sirak, Ya.Ya., Yatsyuk R.A. Corrosion Resistance of Plasma-Electrolytic Layers on Alloys and Coatings of the $\mathrm{Al}-\mathrm{Cu}-\mathrm{Mg}$ System for Various Modes of Heat Treatment. Mater. Sci. 53 (6), $789-795$ (2018). URL: https://doi.org/10.1007/s11003-018-0137-8.

4. Rudnev, V.S., Medkov, M.A., Yarovaya, T.P., Steblevskaya, N.I., Nedovzorova, P.M., Belobeletskaya, M.V. Combination of plasmaelectrolytic oxidation and extraction-pyrolytic method for formation of 
metal oxide layers. Journal of Applied Chemistry 85 (4), 621-628 (2012), URL: https://doi.org/10.1134/S1070427212040155.

5. Borisov, A.M., Krit, B.L., Lyudin, V.B., Morozova, N.V., Suminov, I.V., Apelfeld, A.V. Microarc oxidation in slurry electrolytes: A review. Surf. Eng. Appl. Electrochem. 52, $50-78$ (2016), URL: https://doi.org/10.3103/S106837551601004X.

6. Suminov, I.V., Belkin, P.N., Apelfeld, A.V., Ludin, V.B., Krit, B.L., Borisov, A.M. Plasma-electrolytic modification of the surface of metals and alloys: Book 2. Technosphera, Moscow, 511 p. (2011). In Russian.

7. Walsh, F.C., Low, C.T.J., Wood, R.J.K., Stevens, K.T., Archer, J., Poeton, A.R., Ryder, A. Plasmaelectrolytic oxidation (PEO) for production of anodized coatings on light weight metal (Al, Mg, Ti) alloy. Trans. Inst. Metal Finish. 87 (3), 122-135 (2009). URL: https://doi.org/10.1179/174591908X372482.

8. Filyak, M.M., Kanygina, O.N. Electrophysical properties of anodic aluminum oxide. Bulletin of the Orenburg State University. 9 (158), 240-243 (2013). URL: http://vestnik.osu.ru/2013_9/39.pdf. In Russian.

9. Gutsalenko, Yu.G., Sevidova, O.K. Concept and design and technological development of tools from superhard materials for diamond-spark grinding on universal machines. Reliability of instrument and optimization of technological systems. 40, 35-43 (2017). URL: www.dgma.donetsk.ua/science_public/reliability_instrument/archieve/ № 40.pdf].

10. Tokarev, A.V. Electrophysical characteristics of coatings on aluminum obtained by microarc oxidation. Bulletin of the KyrgyzRussian Slavic University 12 (10), 106-110 (2012). URL: https://krsu.edu.kg/vestnik/2012/v10/a29.pdf. In Russian.

11. Sevidova, E., Gutsalenko, Yu., Rudnev, A., Pupan, L., Titarenko, $\mathrm{O}$. The study of surface microgeometry and morphology of plasma electrolytic oxidation dielectric coatings on aluminum alloys. LNME: Advances in Design, Simulation and Manufacturing II: DSMIE 2019 Conf. Proc., 302-310 (2020), URL: https://doi.org/10.1007/978-3-03022365-6 30.

12. Gutsalenko, Yu.G., Sevidova, E.K., Stepanova, I.I. Evaluation of technological capability to from dielectric coatings on AK6 alloy, using a method of microarc oxidation. Surf. Engin. Appl. Electrochem. 55 (5), 602-606 (2019), URL: https://doi.org/10.3103/S1068375519050041.

13. Gutsalenko, Yu.G. Diamond-spark grinding of high functionality materials. Cursor, Kharkov, 272 p. (2016), http://web.kpi.kharkov.ua/ cutting/dsghfm-monograph.pdf. In Russian. 
14. Dehnavi, V., Liu, X.Y., Luan, B.L., Shoesmith, D.W., Rohani, S. Phase transformation in plasma electrolytic oxidation coatings on 6061 aluminum alloys. Surf. Coat. Tech. 251, 106-114 (2014). URL: https://doi.org/10.1016/j.surfcoat.2014.04.010.

15. Chigrinova, N.M., Chigrinov, V.E., Kukharev, A.A. Formation of coatings by the method of anodic microarc oxidation and their operation in heat-stressed assemblies. Powder metallurgy 5/6, 13-23 (2001). In Russian.

16. Pavlyus, S.G., Sobornitskiy, V.I., Sheprut, Yu.A., Snezhko, L.A., Chernenko, V.I. Dielectric properties of anodic-sparked silicate coatings on aluminum. Electronic Processing of Materials 3, 34-36 (1987). In Russian.

17. Martin, J., Leone, P., Nomine, A., Veys-Renaux, D., Henrion, G., Belmonte, T. Influence of electrolyte ageing on the Plasma Electrolytic Oxidation of aluminium. Surf. Coat. Tech. 269, 36-46 (2015). URL: https://doi.org/10.1016/j.surfcoat.2014.11.001.

18. Hussein, R.O., Northwood, D.O. Production of anti-corrosion coatings on light alloys (Al, Mg, Ti) by Plasma-Electrolytic Oxidation (PEO). In: Developments in Corrosion Protection, 201-239. InTech, Rijeka, Croatia (2014), URL: https://dx.doi.org/10.5772/57171.

19. Chernenko, V.I., Snezhko, L.A., Papanova, I.I. Obtaining of coatings by anode-spark electrolysis. Leningrad, Chemistry, 128 p. (1991). In Russian.

20. Curran, J.A., Clyne, T.W. Porosity in plasma elecrtrolytic oxide coatings. Acta Mater. 54 (7), 1985-1993 (2006). URL: https://doi.org/10.1016/j.actamat.2005.12.029.

21. Gutsalenko, Yu.G., Sevidova, E.K., Stepanova, I.I., Strel'nitskij, V.E. Evaluation of dielectric properties of micro-arc coatings on deformable aluminum alloys. Probl. At. Sci. Technol. 114, 125-127 (2018). URL: https://vant.kipt.kharkov.ua/ARTICLE/ VANT_2018_2/article_2018_2_125r.pdf.

22. Bakovets, V.V., Polyakov, O.V., Dolgovesova, I.P. Plasmaelectrolytic anodic processing of metals. Science, Novosibirsk, 168 p. (1991). In Russian.

\section{Information about author:} Gutsalenko Yu. G., Senior Staff Scientist, National Technical University "Kharkiv Polytechnic Institute" 2, Kyrpychova str., Kharkiv, 61002, Ukraine 